\title{
A experiência moderna de tempo em The Antiquary (1816), de Walter Scott
}

Renata Dal Sasso Freitas ${ }^{1 *}$

\section{RESUMO}

O presente artigo tem como objetivo analisar o romance The Antiquary, do escritor escocês Walter Scott, em sua relação com as transformações no conceito de história no período entre o final do século XVIII e o início do século XIX. Essas transformações dizem respeito não apenas a práticas historiográficas, mas também à própria história enquanto experiência e que, de acordo com as teses de autores como Reinhart Koselleck e François Hartog, fundamentalmente ensejaram a queda do Antigo Regime. O romance de Scott trata do encontro entre um jovem oficial do exército britânico de origem obscura e um antiquário na costa da Escócia na década de 1790. Não apenas ambos lidam com o mistério das origens do jovem oficial, mas também com o impacto das transformaçóes políticas ocorridas no continente e como elas incidem na estrutura da sociedade britânica do período.

Palavras-chave: romance; conceito moderno de história; Walter Scott; historiografia oitocentista; Revolução Francesa.

\section{The Modern Experience of Time in Walter Scott's The Antiquary (1816)}

\section{ABSTRACT}

The present paper aims to analyze the novel The Antiquary, by Scottish writer Walter Scott, in its relationship with the transformations in the concept of history in the period between the end of the $18^{\text {th }}$ Century and the beginning of the $19^{\text {th }}$ Century. These transformations concern not only historiographical practices, but also history itself as a set of experiences that, according to the theses of authors such as Reinhart Koselleck and François Hartog, fundamentally caused the fall of the Ancien Régime. Scott's novel is about the meeting between a young British Army officer of obscure origins and an old antiquary in the coast of Scotland in the 1790s. Both of them deal with the mystery of the young officer's origins, as

DOI: http://dx.doi.org/10.1590/2237-101X01903802

Artigo recebido em 27 de janeiro de 2017 e aprovado para a publicaçáo em 27 de outubro de 2017.

${ }^{1}$ Universidade Federal do Pampa, Bagé, Rio Grande do Sul, Brasil.

* Professora da Universidade Federal do Pampa. E-mail: renatadsf@gmail.com. 
well as with the impact of the political changes that occurred in the continent and how they affected the structure of British society at the period.

Keywords: novel; modern concept of history; Walter Scott; nineteenth-century historiography; French Revolution.

\section{La experiencia moderna del tiempo en The Antiquary (1816), de Walter Scott}

\section{RESUMEN}

El presente artículo tiene como objetivo analizar la novela The Antiquary, del escritor escocés Walter Scott, en su relación con las transformaciones en el concepto de historia durante el período de finales del siglo XVIII e inicios del siglo XIX. Estas transformaciones expresan no sólo prácticas historiográficas, sino también la propia historia en la condición de experiencias que, según las tesis de autores como Reinhart Koselleck y François Hartog, fundamentalmente dieron origen a la caída del Antiguo Régimen. El romance de Scott trata del encuentro entre un joven oficial del Ejército Británico de origen oscura y de un anticuario en la costa de Escocia en la década de 1790. No sólo ambos lidian con el misterio del origen del joven oficial, sino igualmente con el impacto de las transformaciones políticas ocurridas en el continente, y cómo éstas incidieron en la estructura de la sociedad británica del período. Palabras clave: Novela; concepto moderno de historia; Walter Scott; historiografía decimonónica; Revolución Francesa.

Em julho de 1815, em meio a uma viagem entre Paris e Bruxelas, o escritor escocês Walter Scott realizou uma curiosa visita ao local de uma batalha recente, mas carregado de significados históricos urgentes: o campo da Batalha de Waterloo, onde Napoleão Bonaparte havia sido definitivamente derrotado no mês anterior. O autor do sucesso literário Waverley já havia definido, no início daquele ano, que o título de seu próximo romance seria The Antiquary, mas a escrita do romance foi iniciada somente em dezembro, e sua publicação realizada na primavera de 1816 . Scott, incialmente um poeta e compilador de baladas escocesas, gozava entáo de certo status entre a elite britânica, principalmente devido ao mistério que mantinha a respeito da autoria de seus romances, publicados anonimamente. Entre aqueles que desejavam arrancar de Scott a confirmaçáo de que ele era o autor de Waverley e Guy Mannering (1815), estava o próprio príncipe regente da Grã-Bretanha, o futuro George 
IV. ${ }^{2} \mathrm{Na}$ advertência de The Antiquary, o autor escreveu que essa obra era o último volume de uma trilogia sobre o passado escocês, oferecendo em sua última parte uma reflexão sobre os “tempos atuais", em um período de grande conturbação na política europeia após a ascensão e a queda de Napoleáo.

Este artigo tem como objetivo analisar o romance The Antiquary (1819) em sua relação com as transformaçôes no conceito de história no período entre o final do século XVIII e o início do século XIX. Essas transformaçôes dizem respeito não apenas ao método historiográfico e a práticas antiquárias, mas também à ideia de história enquanto experiência e que, de acordo com as teses de autores como Reinhart Koselleck ${ }^{3}$ e François Hartog, ${ }^{4}$ contribuíram de forma fundamental para a Revolução Francesa. Minha proposta é articular o romance de Scott com os debates sobre a aceleração do tempo e da História enquanto experiência, não apenas como parte da história intelectual e do processo de disciplinarização no oitocentos, mas também como uma possibilidade de contribuição à reflexão historiográfica.

Por seu efeito e sua influência sobre a historiografia romântica e por ser considerado o "pai do romance histórico", Walter Scott é um autor incontornável para o estudo da história da historiografia do século XIX. Stephen Bann e Lionel Gossman, por exemplo, salientam o impacto das obras de Scott sobre os historiadores franceses Augustin Thierry e Prosper de Barante. Enquanto Bann se preocupa com os dispositivos práticos da representação do passado, como a noção de cor local, ${ }^{6}$ Gossman explora a relação entre a escrita da história, a literatura e a filosofia, evidente, por exemplo, na adoção do mote do conflito entre raças por Thierry em sua Histoire de la conquête de l'Angleterre par les normands (1825); Thierry reivindicaria uma dívida maior para com Hume e Scott enquanto, como demonstrado por Gossman, a tópica da conquista estaria mais vinculada à filosofia de Jean-Baptiste Say e ao De l'Esprit de conquête et de l'usurpasion (1814), de Benjamin Constant. ${ }^{7}$ A posição na qual Thierry coloca as obras de Scott, contudo, é particularmente

\footnotetext{
${ }^{2}$ Sobre o papel do anonimato no mercado literário anglo-saxão ver: MULLAN, John. Anonimity: A Secret History of English Literature. Princeton, NJ: Princeton University Press, 2008.

${ }^{3}$ KOSELLECK, Reinhart. Futuro passado: contribuição à semântica dos tempos modernos. Rio de Janeiro: Contraponto, 2006.

${ }^{4}$ HARTOG, François. Regimes de historicidade: presentismo e experiências do tempo. Belo Horizonte: Autêntica, 2013.

${ }^{5}$ Em seu ensaio clássico sobre o romance histórico, Georg Lukács define os romances de Scott como inaugurais do gênero tal como o conhecemos hoje. O que os caracterizaria seria seu surgimento após a queda de Napoleão, e seus heróis medíocres sobrevivendo em meio a conflitos civis partidários. É uma das primeiras instâncias em que se estabelece a relação entre o romance histórico oitocentista e a transformaçáo da história enquanto uma experiência no contexto da virada do século XVIII. Ver LUKÁCS, Georg. The Historical Novel. Prefácio de Frederic Jameson. Lincoln, NE: The University of Nebraska Press, 1983.

${ }^{6}$ BANN, Stephen. The Clothing of Clio: a Study of the Representation of History in Nineteenth-century Britain and France. Cambridge: Cambridge University Press, 1984, p. 26.

${ }^{7}$ GOSSMAN, Lionel. Between History and Literature. Cambridge, MA: Harvard University Press, 1990.
} 
reveladora da medida de sua contribuição no desenvolvimento de uma ideia de passado no primeiro quarto do oitocentos.

No caso britânico, Mark Salber Phillips tratou do efeito das obras de Scott sobre o historiador Thomas Babington Macaulay, argumentando que a historiografia, no oitocentos, não teria sido desafiada pela política, pela filosofia e pelas ciências, mas sim pela literatura. Mais especificamente, teriam sido as transformaçôes dos debates literários no final do século XVIII que afetaram a historiografia europeia oitocentista e que não partiram somente do romance scottiano, mas também da poesia de autores como Coleridge e Wordsworth. ${ }^{8}$

O impacto de Scott na historiografia é normalmente atribuído ao seu romance mais famoso, Ivanhoé (1820), que narra as peripécias do personagem-título no contexto do aprisionamento do rei Ricardo I depois do fracasso da Terceira Cruzada, em meio aos conflitos entre normandos e saxôes ainda restantes na Grã-Bretanha do século XII. Porém, em seu momento de publicação, Ivanhoé foi uma virada temática da parte de Scott. Desde que começara a publicar seus romances anonimamente em 1814, suas narrativas majoritariamente tinham como foco as tensóes entre Inglaterra e Escócia depois da Revolução Gloriosa e do Tratado de União de 1707. Ao publicar a primeira edição de The Antiquary, em maio de 1816, Scott adicionou uma advertência à obra, afirmando que ela completava uma série de "narrativas fictícias" cujo propósito era "ilustrar os costumes da Escócia em três períodos diferentes". Enquanto Waverley, de 1814, tinha como foco o levante jacobita de $1745^{\circ} \mathrm{e}$, portanto, a "época de nossos pais", e Guy Mannering (1815) era ambientado no período entre as décadas de 1760 e de 1780, ou seja, o período da juventude de seu autor, The Antiquary, cuja ação se situa "nos últimos anos do século XVIII", tratava do período contemporâneo.

Dentro da perspectiva da história literária, Scott tem sido abordado por diversos autores desde o final do século XX dentro da perspectiva do new historicism ou mesmo de uma chave que problematiza Scott enquanto um autor romântico dedicado a um projeto de idealizaçáo do passado para a Escócia e a Inglaterra. Ina Ferris abordou as obras de Scott em meio a tensóes de gênero não apenas literários: os romances de Scott teriam sido fundamentais para "masculinizar" o romance. ${ }^{10}$ Ian Duncan analisou a relação de Scott com a cidade de Edimburgo, então afetada

\footnotetext{
8 PHILLIPS, Mark. Macaulay, Scott, and the Literary Challenge to Historiography. Journal of the History of Ideas, v. 50, n. 1, p. 117-133, 1989.

${ }^{9} \mathrm{O}$ levante jacobita de 1745 foi a última de várias tentativas de restaurar os Stuart ao poder após a Revolução Gloriosa de 1688 que resultou na deposição de James II. Seu neto, Charles Edward Stuart, entrou na Grã-Bretanha pela Escócia, mobilizando a elite católica e leal à dinastia dos Stuart nas highlands, chegando a entrar em Edimburgo e tentar invadir a Inglaterra pela cidade fronteiriça de Carlisle. Sua derrota final em Culloden, já em 1746, significou uma repressão mais ostensiva às elites escocesas, por meio de leis retirando o direito à jurisprudência dos chefes dos clãs e banindo os trajes típicos das highlands, principalmente o uso do tartan e do kilt.

${ }^{10}$ FERRIS, Ina. The Achievement of Literary Authority: Gender, History and the Waverley Novels. Ithaca, NJ: Cornell University Press, 1991.
} 
pela uniấo com a Inglaterra, e as tentativas, desde o final do setecentos, de transformá-la no "cérebro" da ilha. ${ }^{11}$ Mike Goode apresenta um estudo da noção de "sentimento de história" que teria sido eliminada da historiografia durante o processo de cientifização e institucionalização da disciplina na Grä-Bretanha no século XIX $;^{12}$ as obras de Scott estariam implicadas nesse processo, pois foram rebaixadas ao tipo de "sentimentalização" do passado apenas própria para meninos e, quando muito, mulheres, em um movimento que explica o status das obras de Scott e de outros romances seus contemporâneos ou similares — como o norte-americano James Fenimore Cooper e o brasileiro José de Alencar - como autores infantojuvenis.

Em seu artigo "Reinventando a tradição: sobre antiquarado e escrita da história", Manoel Salgado Guimarães interpreta o romance de Scott como uma instância da construção de uma imagem pejorativa do antiquário na virada do século XVIII, em um momento em que a ideia de antiguidade na Europa ocidental era reconfigurada para não mais remeter à Grécia e à Roma antigas, mas sim a um passado nacional através de descobertas arqueológicas, cujos principais agentes eram os antiquários e não necessariamente os historiadores. ${ }^{13}$ Jonathan Oldbuck, o protagonista do romance, é um deles, preocupado especificamente com a presença romana na fronteira entre a Inglaterra e a Escócia. Porém, Salgado demonstra que a representação das práticas antiquárias de Oldbuck por Scott está imbuída da principal crítica ao tratamento do passado pelos antiquários: sua falta de utilidade, já que essas práticas pareceriam circunscrever o passado nele mesmo, estando assim desligado de uma narrativa mais ampla e desprovido de problematizaçóes históricas.

O estudo de Mike Goode previamente mencionado pormenoriza de uma forma mais aprofundada essa imagem pejorativa não só entre os historiadores, mas também na esfera pública, abordando especificamente o caso de sir William Hamilton, antiquário e embaixador britânico em Nápoles, cuja segunda esposa, Emma, tornou-se amante do almirante Horatio Nelson. $\mathrm{O}$ fato de que Hamilton parecia mais interessado no talento de Emma para performances de "atitudes" — isto é, de posar em cenas de narrativas da Grécia antiga — do que sexualmente tornou-se motivo de chacota em caricaturas do período, nas quais ele era retratado como sendo portador de uma espécie de desvio sexual. ${ }^{14}$ Curiosamente, o antiquário de Scott demonstra a mesma falta de interesse pelo sexo oposto, fato ressaltado também por suas atitudes misóginas.

Meu interesse aqui é a representação da prática antiquária e sua relação com o contexto narrativo do romance, com o objetivo de complexificar a imagem pejorativa do antiquário

\footnotetext{
${ }^{11}$ DUNCAN, Ian. Scott's Shadow: the Novel in Romantic Edimburgh. Princeton, NJ: Princeton University Press, 2007.

${ }^{12}$ GOODE, Mike. Sentimental Masculinity and the Rise of History, 1790-1890. Cambridge: Cambridge University Press, 2009.

${ }^{13}$ GUIMARĀES, Manoel Salgado. Reinventando a tradição: antiquarado e escrita da história. Humanas, v. 23, n. 1/2, p. 111-143, 2000. p. 113-114.

${ }^{14}$ GOODE, Mike. Sentimental Masculinity and the Rise of History, 1790-1890, op. cit., p. 103-104.
} 
que, segundo autores como Manoel Salgado e Arnaldo Momigliano, ${ }^{15}$ fez parte do processo de disciplinarização da história no oitocentos. Como já afirmei previamente, os eventos de The Antiquary ocorrem nos anos de 1790, uma década particularmente turbulenta em termos bélicos, políticos e, sobretudo, intelectuais. Mediante esse cenário de transformaçôes profundas e rupturas históricas, procuro questionar sobre os sentidos possíveis na elaboração da figura de um antiquário enquanto protagonista de um romance ambientado na última década do século XVIII e escrito na esteira da vitória britânica em Waterloo e como ela se relaciona com a ideia de história enquanto experiência neste período.

Assim sendo, em um primeiro momento, abordarei como, conforme sugerido por Mark Salber Phillips e Ruth Mack, as transformaçôes no conceito de história na Grã-Bretanha são evidentes sobretudo em outros gêneros literários que não a historiografia propriamente dita, e como Walter Scott contribui e articula-se com esse fenômeno. Em um segundo momento, demonstrarei como o romance The Antiquary pode ser interpretado como parte dessas transformaçôes, ao explorar as ambíguas relaçóes com o passado representado pelo antiquário Oldbuck.

Os debates recentes na área de história da historiografia, sobretudo do século XIX, estáo norteados pelas teses de Reinhart Koselleck e de François Hartog em torno da perda de força do topos historia magistra vitae na segunda metade do século XVIII. Koselleck parte das mudanças no vocabulário alemão referente à história enquanto um gênero narrativo e suas implicações nas relações de homens e mulheres com o tempo por intermédio das noçôes de campo de experiência e de horizonte de expectativa, ${ }^{16}$ e Hartog propóe o conceito de regime de historicidade para compreendermos essas mesmas relaçôes. ${ }^{17} \mathrm{Em}$ se tratando da proposta de Hartog, é particularmente interessante sua análise do caso de François-René de Chateaubriand como alguém imerso nas transformaçôes das formas de apreensão não apenas de um Novo Mundo no sentido geográfico (já que Chateaubriand é muito conhecido por suas viagens à América do Norte no final do século XVIII), mas também com o novo mundo político e social que emergia na Europa a partir dos acontecimentos de $1789 .{ }^{18}$

É de meu particular interesse aqui relacionar essas duas análises com o contexto letrado britânico do período, que é pouco contemplado pelos autores possivelmente porque, como aponta Ruth Mack, ele não apresenta contribuiçóes explícitas para a filosofia da história e para a ideia da história enquanto um conceito abstrato na forma de tratados. $\mathrm{Na}$

\footnotetext{
${ }^{15}$ MOMiglianO, Arnaldo. História antiga e o antiquário. Traducão de Pedro Telles da Silveira. Anos 90, v. 21, n. 39, p. 19-76, 2014.

${ }^{16}$ KOSELLECK, Reinhart. Futuro passado: contribuição à semântica dos tempos modernos, op. cit.

${ }^{17}$ HARTOG, François. Regimes de historicidade: presentismo e experiências do tempo, op. cit., p. 37-39.

${ }^{18}$ Ibidem, p. 93-129.
} 
Grã-Bretanha, pelo menos à primeira vista, o século XVIII é uma época para se escrever a história em vez de se pensar a respeito dela:

Depois de décadas de queixas sobre a ausência de obras de história sérias, as obras primas de meados do século de David Hume e Edward Gibbon elevaram a Grã-Bretanha à altura da França e da Itália enquanto um país que podia escrever sobre o passado - e mais importante, sobre o seu passado - seguindo o modelo clássico de Tito Lívio, Tucídides ou Tácito. Mas esse modelo de grande prosa histórica, longe de levar a novas teorias da relação entre o passado e o presente, podem ser inclusive visto como funcionando contra esse tipo de pensamento. ${ }^{19}$

Mack sustenta, no entanto, que, entre meados do século XVIII e o início do XIX, a principal esfera de discussão a respeito da relação entre o passado e o presente e sobre a natureza do conhecimento histórico na Grã-Bretanha foi o meio literário, quando o próprio conceito de literatura estava se firmando. Em seu estudo, Mack analisa obras de Samuel Johnson, Henry Fielding, ${ }^{20}$ Charlotte Lennox, Horace Walpole, Lawrence Sterne, William Warburton e, finalmente, do próprio Edward Gibbon, e como elas apresentam questóes como autoria, caráter e consciência históricos de modo a elucidar que o romance histórico e o passado enquanto uma experiência literária emergiram na Grã-Bretanha antes de Scott e da publicação de Waverley em 1814.

Igualmente revelador das mudanças na prática historiográfica na Grã-Bretanha no mesmo período é o trabalho de Mark Salber Phillips sobre sentimento e distância histórica em diferentes gêneros históricos. ${ }^{21}$ Phillips demonstra como algumas das premissas da historia magistra vitae começavam a ruir na Grã-Bretanha através do crescente interesse dos letrados do período no cotidiano e no homem comum, interesse este relacionado ao processo identificado como o "surgimento do romance" no estudo clássico de Ian Watt, de 1957, sobre Defoe, Richardson e Fielding. ${ }^{22}$ Phillips fornece como exemplo das transformaçóes na es-

${ }^{19}$ MACK, Ruth. Literary Historicity. Literature and Historical Experience in Eighteenth-Century Britain. Stanford, CA: Stanford University Press, 2009, p. 3. Todas as traduçôes são de minha autoria.

${ }^{20}$ Para a relação entre Henry Fielding especificamente e seus desafios à historiografia, ver o artigo de GALLAGHER, Noelle. Historiography, the Novel and Henry Field's. Joseph Andrews. SEL Studies in English Literature 1500-1900, v. 52, n. 3, p. 631-650, 2012 e o ensaio de DUARTE, João de Azevedo e Dias. Henry Fielding e a "história verdadeira". In: CHARBEL, Felipe; GUSMÃO, Henrique Buarque de; MELLO, Luiza Laranjeira de S. (Orgs.) As formas do romance: estudos sobre a historicidade da literatura. Rio de Janeiro: Ponteio, 2016, p. 239-265.

${ }^{21}$ PHILLIPS, Mark Salber. Society and Sentiment. Genres of Historical Writing in Britain, 1740-1820. Princeton, NJ: Princeton University Press, 2000.

${ }^{22}$ WATT, Ian. The Rise of the Novel. 2. ed. Berkeley, CA: University of California Press, 2001. O trabalho de Watt já foi naturalmente objeto de revisóes e críticas, entre elas os trabalhos de MCKEON, Michael. The Origins of the English Novel, 1600-1740. Baltimore, MD: Johns Hopkins University Press, 1997; DOODY, Margaret Anne. The True Story of the Novel. New Brunswick, NJ: Rutgers University Press, 1997 e; LIMA, Luiz Costa. O controle do imaginário e a afirmação do romance. São Paulo: Companhia das Letras, 2009. Ver também VASCONCELOS, Sandra Guardini Teixeira. A formação do romance inglês: ensaios teóricos. São Paulo: Hucitec, 2007, que traz também uma coletânea de prefácios e textos críticos do período, de 
crita da história na Grã-Bretanha setecentista a History of Great Britain from the Invasion by the Romans under Julius Caesar (1771-73), de Robert Henry, constituída de sete narrativas simultâneas para cada período abordado, divididas por temáticas desde as mais tradicionais, como a história de instituiçóes militares, religiosas e políticas, até à história das artes, costumes, alimentação, divertimentos etc. De acordo com Phillips, essa escolha sinalizaria "seu reconhecimento de que história tinha que participar de reconceituação do conhecimento social que era uma faceta tão penetrante do pensamento contemporâneo". ${ }^{23}$

Uma das explicaçôes para esse processo estaria nas transformaçôes econômicas da Grã-Bretanha desde o século XVII que a tornaram uma sociedade comercial e que acabaram moldando não apenas o debate político e as políticas de Estado, mas também as preocupaçóes intelectuais dos letrados. Segundo Phillips, essas novas preocupaçóes atingiram a história mais intensamente do que os outros gêneros literários, pois mexiam mais com as convençôes tradicionais da escrita historiográfica.

Uma dessas mudanças foi o surgimento do que Phillips chama de "leitor sentimental", pelo deslocamento da prática da leitura de um processo público e ativo, como no início do período moderno, para uma atividade passiva e privada. No que diz respeito especificamente à história, "ia contra premissas antigas a respeito do valor da instrução histórica e assim ajudou a reformular não somente as dimensôes formais, mas também as morais da prática historiográfica”. ${ }^{24}$ Para compreender como essas mudanças afetam cada gênero, Phillips salienta que é preciso compreendê-los como dentro de uma hierarquia e definidos a partir de seu público. A história, por exemplo, pressupunha um leitor homem, ativo, adulto, em oposição ao romance, cujo público era tido como jovem, feminino e privado, embora a história filosófica voltada para os costumes também fosse, em tese, um gênero considerado aceitável para mulheres.

No contexto da Revolução Francesa, o debate em torno da educação feminina - na esteira dos desafios à ordem do Antigo Regime — problematizou a questão do que as mulheres deveriam ou não ler e os perigos da ficção para as mulheres. Mary Wollstonecraft, refletindo sobre os acontecimentos de 1789, percebeu como o regime de gênero - de leitura, mas em última instância, de sentimento - operava em detrimento das mulheres e contribuía também para a submissão dos homens ao Antigo Regime.

Em resposta principalmente às consideraçóes sobre as mulheres de Jean-Jacques Rousseau em seu romance Julie, ou la nouvelle Heloïs (1761), Wollstonecraft defende a educação das mulheres com ênfase na racionalidade, vista até então como prerrogativa da educaçáo masculina. Serem educadas racionalmente envolvia saber administrar uma casa, reconhecer situaçóes de perigo conjugal (de sedução, principalmente, mas também de se casar com um mau marido),

Richardson e Fielding a Jane Austen.

${ }^{23}$ PHILLIPS, Mark Salber. Society and Sentiment. Genres of Historical Writing in Britain, 1740-1820, op. cit., p. 7.

${ }^{24}$ Ibidem, p. 103. 
mas também dominar um mínimo de política. Uma concepção de leitura feminina interessada e racional emerge desses preceitos, sendo o estudo da história especificamente visto como um equivalente à leitura de romances baratos, caso a leitora o fizesse apenas por entretenimento. ${ }^{25}$

Wollstonecraft, por meio de suas proposiçôes, também sinaliza o esfacelamento do topos da historia magistra vitae. Em seus argumentos a História é poucas vezes mobilizada, já que esse gênero somente teria função para as mulheres a partir do momento em que elas tivessem espaço na arena pública. Em seu texto, Wollstonecraft aponta, sobretudo, para o futuro. $\mathrm{O}$ passado e o presente não a trazem sentimentos bons: seu Vindications of the Rights of Woman (1792) começa pela assertiva de que depois de analisar the historic page e the living world, nada lhe resta a não ser a melancolia diante do estado da mente feminina. ${ }^{26}$ Mais adiante, assevera: "Rousseau se esforça para provar que tudo estava certo 'originalmente': uma porção de autores que tudo está certo agora; e eu, que tudo ficará certo." ${ }^{27}$ Para ela, não há nada que as mulheres possam aprender com a história exceto reconhecer que não tiveram lugar nela ainda.

Esses elementos são relevantes aqui porque os debates em torno da questão de gênero na Grã-Bretanha durante a Revoluçáo foram travados sobretudo por meio do que podemos chamar de "romances filosóficos" escritos majoritariamente por mulheres, entre elas a própria Wollstonecraft, autora de Mary, a fiction (1791) e The Wrongs of Woman (1797). Walter Scott começou a escrever seus romances no rescaldo desse debate e sua prosa foi profundamente afetada pela ficção desse período, mais marcadamente pelas obras da escocesa Elizabeth Hamilton, autora de uma sátira sobre o círculo de Wollstonecraft e William Godwin intitulada Memoirs of Modern Philosophers (1800), e da irlandesa Maria Edgeworth, cuja vasta bibliografia inclui romances com recursos narrativos muito parecidos com os que Scott usará mais adiante, como Castle Rackrent (1800) e The Absentee (1812).

Os romances desse contexto revolucionário, fossem contra ou pró os acontecimentos na França, colocavam em questáo a agência feminina. Obras como as de Frances Burney, Amelia Opie, Charlotte Smith, Jane Austen e da própria Edgeworth, entre outras romancistas, tratam das limitaçôes que as mulheres encontravam para demonstrar suas vontades e controlar seus destinos na sociedade britânica do período, como demonstrado por Claudia Johnson. ${ }^{28}$ Os romances de Walter Scott são parte integrante desse debate, pois repetem muitos dos tropos encontrados em seus enredos e na construção de suas personagens, tanto femininas quanto masculinas; Waverley, por exemplo, está permeado de questôes sobre sentimento e a leitura inadequada de romances. Embora a principal referência de Scott para escrever essa obra seja Tom

\footnotetext{
${ }^{25}$ Ibidem, p. 115.

${ }^{26}$ WOLLSTONECRAFT, Mary. A Vindication of the Rights of Woman and A Vindication of the Rights of Man. Editado por Janet Todd. 3. ed. Oxford: Oxford University Press, 2008, p. 71.

${ }^{27}$ Ibidem, p. 79.

${ }^{28}$ JOHNSON, Claudia L. Equivocal Beings: Politics, Gender and Sentimentality in 1790s — Wollstonecraft, Radcliffe, Burney, Austen. Chicago, IL: The University of Chicago Press, 1995.
} 
Jones, de Henry Fielding, e que essas questóes remontem ao Quixote de Cervantes, Orgulho e preconceito (1813), de Jane Austen, é citado no desfecho do romance. ${ }^{29}$

O status ambíguo do romance nesse período, em que muitos críticos do gênero - como Wollstonecraft, por exemplo - recorrem a ele unicamente para ganhos financeiros ou expor argumentos filosóficos, integrava também o próprio jogo do anonimato estabelecido por Scott no início de sua carreira de romancista. Segundo Jane Millgate, Scott percebia a escrita desse gênero baixo como uma atividade comercial pouco digna de um gentleman e do poeta que frequentava os salôes do príncipe regente e do general Wellington. ${ }^{30}$ No entanto, esse foi o gênero literário escolhido por Scott para refletir sobre o papel da Escócia no Reino Unido dos Hanover e sobre as profundas transformaçóes do final do século XVIII.

The Antiquary começa com seu narrador situando o leitor em um dia de verão, nos últimos anos do século XVIII. Um jovem inglês chamado Lovel toma uma diligência entre Edimburgo e Queensferry rumo a Fairport, conhecendo durante o trajeto Jonathan Oldbuck, um magistrado de meia-idade aficionado por antiguidades, que náo perde tempo em fazer amizade com o rapaz, percebendo-o como um ouvinte em potencial para suas elucubraçōes. Lovel é um desses heróis típicos de Scott: um jovem sensível, estrangeiro na Escócia, cujo ponto de vista o leitor acompanha enquanto os principais personagens do romance são apresentados em todas as suas peculiaridades.

Embora Lovel sirva ao leitor como recurso para decifrar a sociedade de Fairport, ele próprio é um mistério: os motivos de sua viagem nunca são explicados, e um estranho viajando desacompanhado em meio à guerra contra a França Revolucionária, que, no caso, também se tratava de um conflito ideológico, oferece amplos motivos para suspeição. As únicas informaçôes que temos de Lovel em caráter retrospectivo é seu prévio envolvimento com Isabella Wardour, filha de um baronete vizinho de Oldbuck de inclinaçôes jacobitas e similar interesse por antiguidades. Como o próprio antiquário presume acertadamente no início da narrativa, Lovel é o filho bastardo de alguém de posses, logo, inapropriado como marido. Algo que Scott deixa entrever através tanto de Jonathan Oldbuck quanto de sir Arthur Wardour é que o interesse do antiquário é acompanhado por um zelo excessivo por linhagens familiares: Oldbuck não perde tempo em estabelecer sua descendência de um impressor alemáo que migrara para a Escócia no contexto da Reforma. Enquanto sua afiliação

\footnotetext{
${ }^{29}$ SCOTT, Walter. Waverley: or 'tis Sixty Years Since. Editado por Caire Lamont. Oxford: Oxford University Press, 2008, p. 310.

${ }^{30}$ MILLGATE, Jane. Walter Scott: the Making of the Novelist. Edimburgo: Edinburgh University Press, 1984, p. 85-86.
} 
é intelectual, a de Wardour é política, ainda entremeada com os derrotados de 1745; descobrir a linhagem de Lovel e onde ele pertence nesse mundo específico é o principal elemento da trama de The Antiquary.

Em seu estudo clássico de 1963 sobre os romances Waverley, Alexander Welch discute a natureza passiva dos heróis de Scott, algo reconhecido pelo próprio escocês ao anonimamente escrever uma crítica ao primeiro volume de sua série Tales of my Landlord, em 1817 — um ano depois da publicação de The Antiquary, portanto. De acordo com o próprio Scott e outros críticos contemporâneos seus, entre eles John Leycester Adolphus ${ }^{31}$ e William Hazlitt, os heróis de seus romances seriam conduzidos pelos eventos nos quais se envolviam em vez de interferirem por meio de açóes e decisôes.

De acordo com Scott, a inaçáo do herói - muitas vezes prisioneiro, inconsciente ou simplesmente ausente - tinha a função narrativa de servir como meio para descriçôes de detalhes topográficos e históricos. Os protagonistas de Scott são quase sempre, tanto quanto o leitor, estrangeiros visitando a Escócia pela primeira vez, em uma tópica recorrente nessa ficção autoetnográfica sobre as diferentes nações da Grã-Bretanha; ${ }^{32}$ sua inação, portanto, derivaria de seu estranhamento diante de novas circunstâncias. A conclusão a qual Welch chega, contudo, é que a passividade dos protagonistas de Scott se deve ao regime de prudência inaugurado diante dos acontecimentos da Revolução Francesa e defendidos principalmente por Edmund Burke em suas Reflections on the Revolution in France (1791), ${ }^{33}$ em que gentlemen como os protagonistas de Scott deveriam renunciar ao direito de se autogovernar em prol da manutenção da sociedade civil. De acordo com Welch, homens como Waverley e Lovel vivem em um mundo burkeano em que a civilização e a barbárie (seja dos levantes jacobitas do século XVIII ou da Revolução Francesa) não podem coexistir, tornando-se, assim, meros espectadores quando em meio a ela.

O conservadorismo de Scott — isto é, sua reação ao processo revolucionário francês — não se manifestava apenas na forma de sua aderência à interpretação burkeana da Revolução Francesa. Scott já era um poeta de algum renome quando começou a publicar seus romances, e a especulação em torno de ele ser ou não realmente seu autor o impulsionou para a vida pública. No conturbado

\footnotetext{
${ }^{31}$ O jurista John Leycester Adolphus ficou particularmente famoso por escrever as Letters to Richard Heber, Esq. (1821), em que buscava provar que o autor de Marmion (1808), poema épico sobre a batalha de Flodden, era o poeta Walter Scott. Para tanto, Adolphus apontava as semelhanças de estilo e caracterização entre os romances e o poema.

32 The Absentee (1800), de Maria Edgeworth, por exemplo, trata de um jovem herdeiro de um título nobiliárquico ligado a vastas propriedades na Irlanda, mas cuja família tem residência fixa em Londres, daí o título. A trama se desenvolve fundamentalmente em meio a uma visita do protagonista, Colambre, às terras de sua família, o estranhamento perante à realidade da Irlanda rural e as consequências nefastas do estilo de vida de seus pais. Sobre autoetnografia e o romance britânico no século XIX, ver BUZARD, James. Disorienting Fiction: the Autoethnographic Work of Nineteenth-Century British Novels. Princeton, NJ: Princeton University Press, 2005. ${ }^{33}$ WELCH, Alexander. The Hero of the Waverley Novels. 3. ed. Princeton, NJ: Princeton University Press, 1992, p. 35-39.
} 
ano de $1819,{ }^{34}$ Scott propôs a formação de milícias de trabalhadores rurais e pequenos proprietários para reagir a uma possível insurreição na Escócia. Tais milícias deveriam inclusive vestir-se como os highlanders sobre os quais ele escrevia em seus romances. Segundo Miranda Burgess, o autor de Waverley percebia sua Escócia como "preso entre um passado enquadrado enquanto jacobita e um futuro jacobino ameaçador" ${ }^{35}$ Três anos mais tarde, Scott seria o principal agente por trás da visita do rei George IV a Edimburgo, inclusive com o retorno do uso do tartan kilt como o traje nacional escocês, um momento-chave na formação de uma identidade nacional britânica.

Como demonstra Burgess, essas não foram as primeiras ocasiōes em que Scott lançou mão do passado escocês para enfrentar o novo radicalismo advindo da França e ganhando aos poucos eco nas reivindicaçóes por reformas sociais na Grã-Bretanha. Um dos elementos que caracterizariam o que a autora chama de "nacionalismo antiquário" de Scott está nesse paralelo estabelecido entre jacobitas e jacobinos, em um procedimento literário bastante confuso. Especificamente em The Antiquary, trata-se de uma possível invasão francesa no trecho do litoral escocês em que Scott situa a fictícia Fairport. Só que todos os elementos jacobitas da narrativa nessa ocasião deixam de representar o invasor para, em vez disso, protegerem a ordem vigente. Eles são, como afirma Burgess, "tirados da história para serem revividos e recontextualizados como ornamentos teatrais de uma Escócia hanoveriana”, reconfigurando, assim, a narrativa nacional da Grã-Bretanha: "fundindo jacobitas com jacobinos em seu simulacro de invasão e voluntarismo, Scott quebra com a oposição entre eles e reconfigura a história da Escócia no passado evolucionário do presente comercial da Grã-Bretanha." ${ }^{36}$

Essa reconfiguração narrativa é sobretudo teleológica, embora ela seja reacionária e profundamente marcada por retornos, como na figura dos jacobitas. Porque, sobretudo no caso de The Antiquary, não se trata apenas de uma reordenação dos eventos em um passado escocês, mas de um processo de reinscrição do passado com o propósito de projetar um futuro britânico. Como veremos a seguir, esse procedimento parece pouco ter a ver com a escrita historiográfica "científica” que surgiria na década seguinte, e não apenas produzirá resultados semelhantes como também afetará particularmente seus protocolos narrativos.

\footnotetext{
${ }^{34}$ No ano de 1819, quando a Grã-Bretanha estava ainda assolada pela crise depois das décadas de guerra contra a França, viu culminar o debate e as mobilizações demandando sufrágio universal. $\mathrm{O}$ ápice das tensôes se deu no Massacre de Peterloo, em Manchester, quando a cavalaria fez uma carga contra a multidáo composta de entre 60 mil a 80 mil pessoas, ferindo centenas e matando 15 . Uma análise especialmente relevante da literatura britânica tendo esse ano como fio condutor é England in 1819, de James Chandler (1998). Chandler toma como ponto de partida um poema de Percy Byssche Shelley intitulado England in 1819, mas que, como o próprio Chandler salienta, teve esse título atribuído postumamente por Mary Shelley, que cogitara também chamá-lo England in 1820. As tensões sociais na Grã-Bretanha não terminaram em 1819, portanto; a reforma parlamentar expandindo o direito a voto só entrou em vigor em 1832.

${ }^{35}$ BURGESS, Miranda J. Scott, History and the Augustan Public Sphere. Studies in Romanticism, v. 40, p. 123-170, 2001, p. 123. Burgess refere-se aqui respectivamente aos movimentos pró-Stuart do século XVIII, que advogavam por um retorno à primazia do catolicismo, e ao regime do Terror, ainda vigente no momento em que se passa o romance de Scott.
}

${ }^{36}$ Ibidem, p. 128. 
Para além dos heróis passivos, um dos aspectos que ligam a trilogia iniciada em 1814 é justamente a restauração de herdeiros perdidos: em Waverley, o protagonista perde-se em meio às lealdades de seu pai, um militar leal aos Hanover, e o tio de quem é herdeiro, partidário dos Stuart; Guy Mannering, or the Astrologer (1815) trata do retorno de Harry Bertram, sequestrado quando bebê por contrabandistas na costa da Escócia, às propriedades de seu pai, e dos seus encontros e desencontros com o personagem-título, que previra nos astros seu futuro turbulento no dia de seu nascimento. Todos esses atos de restauração, no entanto, como o próprio processo de ressignificação do passado escocês empreendido por Scott em 1819 e 1822, apontam bem mais para o futuro do que para o passado em si. Embora provenientes da elite escocesa católica, vinculada aos Stuart e às dinâmicas feudais dos clâs, esses herdeiros não dão continuidade às suas práticas — políticas ou religiosas —, encaixando-se em uma Grã-Bretanha moderna e protestante. O passado vira relíquia, como o quadro de Edward Waverley e de Fergus McIvor em trajes das highlands que decora a propriedade deste primeiro ao final da narrativa do romance em que é personagem-título.

No entanto, esse ato antiquário não está desprovido de ambiguidades. Como Yoon Sun Lee já demonstrou, a relação entre as práticas antiquárias de Scott e seu conservadorismo político reativo à Revolução Francesa é mais complicada do que parece. É muito tentador associar o historicismo de matriz britânica a práticas antiquárias vinculadas à tradiçẫo empírica do Iluminismo escocês, sobretudo em contraposição à filosofia especulativa francesa. Contudo, mesmo Edmund Burke e, como veremos, Scott são profundamente críticos do antiquariado enquanto forma de relação do passado. Burke é o principal responsável por introduzir a herança enquanto metáfora no vocabulário político do período. Como afirma Lee,

(...) As Reflections de Burke subvertem qualquer entendimento literal ou literalista de autenticidade histórica. Enquanto Burke exibia dramaticamente um profundo apreço pelos arquivos e pelos repositórios da história britânica para desacreditar seus oponentes, seu argumento maior sobre a constituiçáo britânica identifica a verdade da história com a utilidade de uma narrativa de herança contínua, de sorte nunca diminuída, de relevância e significado para a formação do caráter nacional. Em vez de essencializar o caráter nacional, Burke argumenta nas Reflections que certas ficções mediadoras estão no cerne do que se passa por autoconhecimento coletivo da Grã-Bretanha. ${ }^{37}$

Essa ligação com a herança, sustenta Burke, não deve em hipótese alguma, no entanto, se assemelhar às "superstiçôes" dos antiquários, mas sim seguir o espírito da "analogia filosófica”. Ironicamente, Burke era acusado de assemelhar-se a um antiquário por seus rivais. ${ }^{38}$

\footnotetext{
${ }^{37}$ LEE, Soon Yun. A Divided Inheritance: Scott's Antiquarian Novel and the British Nation. ELH, v. 64, n. 2, p. 537-567, 1997, p. 525.

${ }^{38}$ GOODE, Mike. Sentimental Masculinity and the Rise of History, 1790-1890, op. cit., p. 69-79.
} 
Tendo em vista a péssima reputação dos antiquários nesse período, portanto, não surpreende que The Antiquary seja, em parte, uma autossátira, visto que Walter Scott iniciou sua carreira letrada por meio do antiquariado. Jonathan Oldbuck é dado às excentricidades tipicamente identificadas com esses homens: seu gabinete é tomado pela desordem; suas disputas com sir Arthur são aparentemente mesquinhas; ele parece ver antiguidades onde elas não estão. No quarto capítulo do romance, Oldbuck tenta mostrar para Lovel uma de suas descobertas: o que ele julga serem os resquícios de um acampamento militar romano. Para constrangimento de ambos, surge o mendigo Edie Ochiltree, afirmando que ele e outros andarilhos haviam, há apenas vinte anos, construído a estrutura que Oldbuck e Lovel estavam observando, para o casamento de um certo Aiken Drum. A inscrição que o antiquário julga significar Agricola Dicavit Libens Lubens, na verdade queria dizer Aiken Drum's Long Ladle, uma piada de Ochiltree e seus companheiros com o fato de o noivo ser um homônimo de um personagem de uma canção de ninar jacobita. ${ }^{39}$

Além disso, em uma passagem particularmente famosa do romance, Oldbuck demonstra não estar preocupado com a autenticidade das narrativas que seus estudos antiquários poderiam justificar. Em suas tentativas de despistar os motivos de sua estada em Fairport, Lovel dá a entender a Oldbuck que tem ambiçôes literárias. O antiquário passa então a aconselhar o jovem sobre o que escrever:

“(...) Tem que ser algo ao mesmo tempo sólido e atraente — nada de seus romances ou novidades anômalas — Eu faria você tomar o terreno elevado de uma vez — Deixe-me ver O que você acha de um épico verdadeiro? - o bom e velho poema histórico que durava uns 12 ou 24 livros - faremos assim - Eu lhe darei um tema - A batalha entre os caledônios e os romanos - A Caledoníada; ou invasão repelida - Deixe esse ser o título - ele irá servir para o gosto atual e você pode colocar um toque dos tempos."

"Mas a invasão de Agrícola nâo foi repelida."

"Não, mas você é um poeta — livre da corporação e tâo preso à verdade ou à probabilidade quanto o próprio Virgílio - Você pode vencer os romanos a despeito de Tácito." ${ }^{40}$

A proposta de Oldbuck inclui que não só ele providencie as notas críticas e históricas para cada um dos cantos, mas também escreva a própria estrutura do poema. Segundo Burgess, isso atestaria o poder de um produtor cultural — em oposiçáo a um historiador ou mesmo a um antiquário - de mover-se entre o passado e o presente, entre os artefatos e a invenção: "A derrota da verdade antiquária dá lugar à historiografia mais magistral e triun-

\footnotetext{
${ }^{39}$ SCOTT, Sir Walter. The Antiquary. Editado por Nicola Watson. 2. ed. Oxford: Oxford University Press, 2009, p. 41-44.

${ }^{40}$ Ibidem, p. 134-135.
} 
falista precisamente porque ela é abertamente artificial, demandando o consentimento tanto do autor quanto do leitor." ${ }^{\text {‘1 }}$

Apesar dos arroubos de Oldbuck, ele é peculiarmente cético em comparação ao seu vizinho e rival sir Arthur Wardour. Uma das subtramas do romance envolve sir Arthur sendo enganado por um mágico charlatão alemão chamado Dousterswivel a respeito da existência de um tesouro escondido em meio às ruínas de uma abadia em sua propriedade. Oldbuck recrimina Wardour - e outros que se interessam pelo sobrenatural — por suas superstiçóes.

Mike Goode aponta que The Antiquary apresenta três modelos diferentes de masculinidade que conviviam na virada do setecentos e, em consequência, três modelos de relação com o passado. Por um lado, temos Lovel, o protagonista, um típico man of feeling do período, que tem um interesse genuíno no passado e que serve como um contrapeso aos delírios antiquários de Oldbuck. Em outro extremo estão sir Arthur, cuja leitura equivocada e supersticiosa do passado não é apropriadamente masculina por implicar, na verdade, uma fuga da história para o romanesco; e Oldbuck, que demonstra uma incapacidade de viver o presente - "seu gosto por passatempos históricos o levam demasiadamente à história" ${ }^{42}$ Por conta dessa sua disfunção de experiência temporal, ou Oldbuck não consegue compreender o passado eficientemente, como é o caso do acampamento romano, ou entáo náo se importa com a veracidade das narrativas que os indícios que coleta possam constituir.

É particularmente interessante, portanto, o fato de que depois de ler Quentin Durward (1823) — um romance de Scott sobre um arqueiro a serviço de Luís XI —, Leopold von Ranke, representante máximo da história factual baseada em documentos oficiais, tenha decidido guardar distância de toda a forma de invenção e imaginação em suas próprias obras. ${ }^{43}$ $\mathrm{Na}$ esteira das perturbações que a Revolução Francesa e mais tarde Napoleão causaram na Europa, tanto derrotar os romanos a despeito de Tácito quanto ater-se minuciosamente aos fatos serviam para configurar narrativas nacionais.

É importante salientar que Scott, como romancista, não era despreocupado com a veracidade e a probabilidade dos eventos presentes em seus romances. Ele foi particularmente minucioso em sua descriçáo dos eventos do levante jacobita de 1745 em Waverley, por exemplo. Quando reeditou suas obras em 1829, no que chamou de Magnum Opus, Scott se viu compelido a adicionar notas explicativas, não apenas comentando o texto, mas também respondendo a críticas - como é o caso de uma extensa nota sobre sua caracterização de Charles Edward Stuart —, e comentando as diferentes fontes históricas utilizadas na composiçáo do romance. ${ }^{44} \mathrm{O}$ mesmo procedimento foi adotado com suas obras subsequentes,

\footnotetext{
${ }^{41}$ BURGESS, Miranda J. Scott, History and the Augustan Public Sphere, op. cit, p. 132.

42 " his pleasures in historical pursuits lead him too much into history." GOODE, Mike. Sentimental Masculinity and the Rise of History, 1790-1890, op. cit., p. 99.

${ }^{43}$ BANN, Stephen. The Clothing of Clio: a Study of the Representation of History in Nineteenth-Century Britain and France, op. cit., p. 23.

${ }^{44}$ SCOTT, Sir Walter. Waverley: or 'tis Sixty Years Since, op. cit., p. 404-407.
} 
mas o caso de Waverley é peculiar porque esse romance trata de acontecimentos específicos do passado escocês. $\mathrm{O}$ fato de que essas notas só foram adicionadas 15 anos depois de sua publicação original não deixa de ser interessante, sugerindo caminhos possíveis para o futuro da investigação que apresento aqui.

$\mathrm{O}$ argumento que proponho aqui é que tanto a historiografia dita científica do século XIX quanto o romance histórico estabeleceram narrativas teleológicas a respeito do estado-nação na Europa ocidental, mas que ambos se fundamentam em uma rejeição à especulação filosófica. Mesmo que Walter Scott fosse um antiquário e elaborasse ficçôes que pareciam, à primeira vista, despreocupadas com os "fatos", ele próprio rejeitava a ideia de uma abordagem narrativa do passado desprovida de conexáo com o presente e, principalmente, com um projeto de futuro. Como já afirmado aqui, as narrativas de Scott apontam para um futuro britânico em que o passado jacobita da Escócia seria superado para sua inserção no corpo político do Reino Unido. Seus romances, elaborados a partir da tópica da restauração do herdeiro perdido, não indicam um retorno ao passado: os herdeiros, criados fora da tradição de suas famílias, implicam uma linhagem que é restaurada, deslocando contudo a trajetória dessas famílias escocesas tradicionais ao protestantismo da dinastia de Hanover e, na época do próprio Walter Scott, no poder representado por George III e depois George IV.

Um dos aspectos mais marcantes de The Antiquary é justamente a forma com que temporalidades diversas convergem ao longo da narrativa. Não se trata aqui apenas de recuos temporais ou de anacronismos, mas sim de diferentes tempos invadindo a topografia da trama; utilizo aqui topografia porque identifico uma representação da história enquanto força atuante nos espaços do romance. Um exemplo sáo os cômodos da Glenallan-house, propriedade de uma das famílias jacobitas e católicas:

Eles eram vastos e extensos, mobiliados de forma a mostrar a importância e o esplendor antigos da família. Mas todos os ornamentos eram de acordo com o gosto de um período anterior e distante, e quem ali estivesse poderia se supor estar atravessando os aposentos de um nobre escocês antes da união das coroas. A falecida condessa, parte por um desprezo arrogante acerca dos tempos em que vivia, parte por seu senso de orgulho familiar, não havia permitido alteraçóes ou modernizaçóes na mobília durante sua residência na Glenallan-house. A parte mais magnífica da decoraçáo era uma coleçáo valiosa de quadros pintados pelos melhores mestres, cujas molduras enormes estavam um pouco avariadas pelo tempo. Nesse quesito também o gosto sombrio da família parecia predominar. Haviam alguns belos retratos da família por Vandyke e outros mestres eminentes; mas a coleçáo era mais rica nos santos e martírios de Domenichino, 
Velázquez, Murillo e outros temas do mesmo tipo, que haviam sido selecionados em detrimento de paisagens e peças históricas. A maneira com a qual esses temas horríveis e por vezes repugnantes eram representados harmonizavam com o estado dos aposentos (...).45

Um dos motes de The Antiquary é a resistência ao sentimento que Koselleck e Hartog identificam como uma aceleração do tempo frente aos acontecimentos do fim do século XVIII. Se a condessa de Glenallan se recusa a aceitar a derrota política dos partidários dos Stuart, outros habitantes de Fairport também lamentam os efeitos do tempo. Entre eles está Caxon, o barbeiro de Oldbuck, que lamenta profundamente o fato de que o jovem Lovel não tem necessidade de seus serviços: "duvido que você vá querer que eu amarre seu cabelo, já que (com um suspiro delicado) todos os jovens usam cabelo curto agora." ${ }^{\circledR 6}$ Caxon é o responsável por cuidar das últimas três cabeças que ainda carregam perucas em Fairport, entre elas a do próprio Oldbuck. O narrador explora esse contraste histórico por meio da comparação entre o desjejum de Oldbuck e de Lovel, descrevendo a pesada mistura de rosbife e mum, uma cerveja forte de trigo e ervas amargas, "da qual a geração atual somente conhece seu nome por ele aparecer nas leis de receita do parlamento", com o hábito "moderno" de tomar chá ou café pela manhã do qual Lovel é adepto e que o antiquário se recusa terminantemente a adotar. ${ }^{47}$

Maxwell aponta uma das contradiçôes peculiares de Jonathan Oldbuck que rompe com o estereótipo pejorativo do antiquário da década de 1790: Oldbuck, embora misture temporalidades, reconhece a emergência do tempo. Quando ele e Lovel se conhecem, ambos estão aguardando uma diligência que está atrasada. $\mathrm{O}$ atraso é um problema sério: ambos precisam tomar uma balsa para cruzar o estreito de Queensferry antes que a maré vire. O primeiro dos longos discursos do antiquário aos quais Lovel é submetido versa justamente sobre a precária infraestrutura dos transportes na Escócia. Os perigos de não levar em consideração as marés aparece novamente quando sir Arthur e Isabella Wardour deixam a propriedade de Oldbuck rumo à sua e decidem ir pela praia, junto aos penhascos. Oldbuck e Lovel, ao deduzirem a potencial tragédia, correm para salvá-los, competindo sugestivamente com a velocidade e a força das ondas, que empurravam a carruagem dos Wardour cada vez mais de encontro aos rochedos.

Maxwell associa essas cenas com a ideia de "inundações de tempo", retirada de uma passagem da Life of Napoleon (1827) do próprio Scott, mas que advém das reflexóes do escocês em sua viagem ao continente europeu em julho de 1815, pouco depois de um mês da batalha de Waterloo. A viagem resultou em um dos textos políticos de Scott, Paul's Letters to his Kinfolk, que, segundo Maxwell, "sugere tanto as possibilidades quanto os limites da busca de

\footnotetext{
${ }^{45}$ SCOTT, Sir Walter. The Antiquary, op. cit., p. 273.

${ }^{46}$ Ibidem, p. 102.

${ }^{47}$ Ibidem, p. 104.
} 
Scott pela história sendo feita”. Nele, o narrador se depara com os desafios de ser um repórter transformado em historiador, lutando para representar fatos que a memória popular já esqueceu. O mesmo ocorre quando, em 1816, ele decide escrever um register de 1814, com o qual teve muitas dificuldades. Como Maxwell afirma, "o cronista de seu próprio tempo havia se tornado um historiador do passado, jogado de volta em seu papel antiquário original. Mas com a seguinte diferença: ele agora estava reconstruindo uma era em que ele havia vivido, em vez de uma sobre a qual ele havia apenas ouvido ou lido a respeito". ${ }^{48}$

Ao escrever a biografia de Napoleão, uma década mais tarde, Scott compara os eventos históricos a um dilúvio, que atordoa os sentidos de quem os experimenta, perturbando inclusive as lembranças subsequentes. "No entanto, fazer isso é a província peculiar da história, que será escrita e lida em vão, a não ser que ela possa ligar a seus detalhes uma ideia acurada da impressão que esses eventos produziram nas mentes dos homens enquanto eles ainda estavam em seu trânsito". ${ }^{49}$ Dez anos depois, Scott sistematiza o que queria dizer com todas aquelas irrupções, tanto das turbulentas águas da costa da Escócia quanto de diferentes temporalidades em The Antiquary. Ambas causam semelhante ansiedade e deixam suas vítimas, nas formas da condessa de Glenallan, do jovem pescador Steenie Mucklebackit e da jovem Eveline Neville.

Joscelind, a condessa de Glenallan, é introduzida pela primeira vez na narrativa em seu próprio funeral, conduzido clandestinamente nos ritos católicos em meio às ruínas da abadia de St. Ruth. A cerimônia é descrita do ponto de vista do charlatão Dousterswivel, que "ainda permanecia em dúvida se o que ele via era substancial ou uma representação terrena dos ritos que, em tempos passados, eram familiares em meio essas paredes, mas que agora eram raramente praticados em países protestantes e quase nunca na Escócia”. ${ }^{50}$ Dousterswivel não acredita no que vê, pois o catolicismo, na narrativa scottiana, pertence ao passado. A condessa de Glenallan, tanto quanto as próprias ruínas onde está sendo sepultada, é uma das vítimas do tempo histórico. Ela não tem mais lugar na narrativa e seu funeral, assim com as decoraçôes de sua residência, fazem o visitante se sentir deslocado temporalmente.

Steenie Mucklebackit, por outro lado, é vítima da onipresente fúria das águas no romance. Entre a morte da condessa e a sua, a avó do rapaz, Elspeth, que até então aparentava estar demente, manda uma mensagem e um anel para o filho da falecida condessa. É em meio a esses dois funerais, momentos que definem um tempo em transformação e um passado em sepultamento, que o mistério em torno das origens de Lovel começa a ser resolvido. Esse processo se dá com a ausência de Lovel, que por conta de um duelo é forçado a fugir de Fairport; o típico herói de Scott, portanto, cujo destino é determinado pelos acontecimentos, em vez de ele próprio resolvê-lo.

\footnotetext{
${ }^{48}$ MAXWELL, Richard. The Historical Novel in Europe, 1650-1950. New Haven, CT: Yale University Press, 2012, p. 72.

${ }^{49}$ SCOTT apud MAXWELL, Richard. The Historical Novel in Europe, 1650-1950, op. cit., p. 73.

${ }^{50}$ SCOTT, Sir Walter. The Antiquary, op. cit., p. 253-254.
} 
A morte de Eveline Neville é revelada pela velha Elspeth em seu encontro com Glenallan. Elspeth, como Edie Ochiltree, é um repositório de memória que sobrevive ao turbilhão e que desafia as convicçôes daqueles que o tentam decifrar. Curiosamente, ela remete ao próprio passado de Oldbuck, já que ele havia sido apaixonado por Eveline Neville 20 anos antes. Eveline era uma agregada dos Glenallan a quem a velha condessa mente que cometeria incesto caso se unisse ao homem por quem era apaixonada, o jovem lorde Geraldin, filho de Joscelind. Tendo casado em segredo com Geraldin e já grávida, Eveline tenta o suicídio no mar. É resgatada apenas a tempo de dar à luz a um menino, que é criado pelo tio paterno, sem saber sua real identidade. Geraldin tampouco sabe o destino da criança ou que de fato não havia se envolvido com a própria irmã. Perante essa revelação romanesca, não custa muito para Oldbuck e o próprio Geraldin, agora conde de Glenallan, desvendarem a identidade do herdeiro secreto. A morte de Eveline sugere uma tentativa de fuga do indivíduo que náo consegue lidar com o turbilhão de acontecimentos, principalmente quando eles apontam à uma falsa realidade.

A metáfora aquática aqui é distinta à de outro antagonista do processo revolucionário francês, embora sirva para os mesmos propósitos políticos. Refiro-me aqui às duas margens do rio descrito por François-René de Chateaubriand em suas reflexôes sobre o mundo antes e depois da Revolução Francesa. Curiosamente, a imagem conjurada por Chateaubriand é plácida, embora ele tenha sido atingido pelo processo revolucionário muito mais intensamente do que o próprio Walter Scott. Antes de Scott, Chateaubriand também se sentira incapaz de descrever os eventos que testemunhava, mas em vez de imaginar-se um historiador do passado recente, Chateaubriand sentia-se apenas impotente, vendo-se obrigado a descartar suas páginas. ${ }^{51}$ Como já afirmei, é a Chateaubriand que François Hartog recorre para explicitar o sentimento de deslocamento causado pelas mudanças na experiência de tempo ocorridas no final do século XVIII. Na distante Escócia, as águas plácidas do rio cruzado pelo francês davam a impressão de causar um maremoto.

É importante ressaltar que enquanto os letrados britânicos reagiam às Reflections on the Revolution in France, de Edmund Burke, Chateaubriand partia para os Estados Unidos "com Rousseau embaixo do braço". Nos primeiros anos do novo século, publicou os romances Atala e René, que descreviam a vida dos nativos da América do Norte. Ao mesmo tempo que a Grá-Bretanha se autoetnografava, como mencionado anteriormente, o romance histórico era usado também para contemplar e organizar a realidade do Novo Mundo nos gêneros narrativos do Velho. Mais tarde, outros romancistas, leitores de Chateaubriand e Scott, como James Fenimore Cooper, nos Estados Unidos, e José de Alencar, no Brasil, se apropriaram das estruturas narrativas teleológicas, principalmente dos romances de Scott, para representar os passados de suas respectivas naçóes. O senso comum geralmente difundido é que estes autores remetiam-se principalmente a Ivanhoé, o romance medieval em que ele mais ousou idealizar um passado para a Grã-Bretanha, ignorando o caráter presentista,

\footnotetext{
${ }^{51}$ HARTOG, François. Regimes de historicidade: presentismo e experiências do tempo, op. cit., p. 111.
} 
teleológico e reflexivo de seus romances anteriores. No que diz respeito a Ivanhoé, não por acaso ele apresenta uma dedicatória na forma de uma carta do autor fictício da obra, um certo Laurence Templeton, que pede permissão para dedicá-la ao reverendo Jonas Dryasdust, ${ }^{52}$ afirmando que a obra é baseada em um manuscrito encontrado na coleção do antiquário sir Arthur Wardour. O próprio Scott reconhece Ivanhoé, portanto, como uma de suas ficções antiquárias.

Busquei aqui fazer algumas consideraçóes sobre como o romance The Antiquary de Walter Scott pode ser analisado à luz das duas principais teses que norteiam os debates em torno da história da historiografia atualmente. Explorando a bibliografia recente sobre a relação entre Scott e a escrita da história e, especificamente, sobre The Antiquary e as mudanças na concepção de história na virada do século XVIII, grande parte da produção procurava estabelecer ou rever os nexos entre as práticas antiquárias de Scott e o estabelecimento de uma identidade nacional britânica no século XIX. Mesmo a interpretação original de Mike Goode, propondo a análise de um "sentimento de história" em oposição à "ideia de história” de R. G. Collingwood, e que afirma que The Antiquary pode ser lido como uma "história da história" do final do século XVIII, é mais restrita ao contexto britânico e às questôes de gênero (gender), que são o cerne de seu argumento.

The Antiquary é narrativamente um dilúvio, semelhante à imagem evocada para o curso dos acontecimentos históricos. Não explorei aqui, por exemplo, os elementos góticos presentes no romance e que significado eles podem ter perante as turbulências políticas do período que ele almeja representar. Também não me aprofundei na subtrama envolvendo o alemão Dousterswivel, que inclui uma pausa de um capítulo inteiro para que Isabella Wardour narre uma lenda alemã aparentemente desconexa do enredo. Todos esses aspectos certamente poderiam contribuir para meus argumentos, mas preferi me ater às questóes mais latentes relativas à experiência de tempo, e suas conexóes com os debates sobre a escrita da história na virada do século, e menos imbricadas nas reviravoltas narrativas do romance.

Scott de fato ficou mais conhecido por seus romances ambientados na Idade Média, como Ivanhoé. Porém, como apresentado anteriormente, o máximo que Scott havia recuado no tempo era até então a Revolução Gloriosa, ponto de partida para os conflitos civis que seus romances retratam. Como Maxwell salienta, inclusive, a trilogia com a qual Scott começou sua carreira de romancista - Waverley, Guy Mannering e The Antiquary - se aproximam do presente, em vez de recuar no tempo. ${ }^{53}$ No período que trato aqui, portanto, o

\footnotetext{
52 "Dry as dust", ou "seco como poeira".

${ }^{53}$ MAXWELL, Richard. The Historical Novel in Europe, 1650-1950, op. cit., p. 76.
} 
projeto de Walter Scott é orientado para uma reelaboração narrativa de uma história recente, marcada por transformações e debates políticos do século XVIII.

Levando em consideração o contexto letrado em que Scott estava e as tensóes por ele exploradas em The Antiquary, podemos de fato inferir, como fez Manoel Salgado Guimarães, que ele estava escrevendo justamente no momento em que a prática antiquária estava sendo excluída da escrita da história. ${ }^{54}$ No entanto, talvez possamos constatar que Scott tenha encontrado no romance - esse gênero mais maleável, aberto, ainda em formação — uma forma de conjugar duas práticas aparentemente incompatíveis: a escrita de uma história orientada por um sentido filosófico e ao mesmo tempo erudita, ainda que, como Virgílio, ele estivesse livre das obrigaçóes da corporação.

\section{Referências bibliográficas}

BANN, Stephen. The Clothing of Clio: a Study of the Representation of History in Nineteenth-Century Britain and France. Cambridge: Cambridge University Press, 1984.

BURGESS, Miranda J. Scott, History and the Augustan Public Sphere. Studies in Romanticism, v. 40, p. 123-170, 2001.

BUZARD, James. Disorienting Fiction: The Autoethnographic Work of Nineteenth-Century British Novels. Princeton, NJ: Princeton University Press, 2005.

CHANDLER, James. England in 1819. The Politics of Literary Culture and the Case of Romantic Historicism. Chicago, IL: The University of Chicago Press, 1998.

DOODY, Margaret Anne. The True Story of the Novel. New Brunswick, NJ: Rutgers University Press, 1997.

DUARTE, João de Azevedo e Dias. Henry Fielding e a "história verdadeira". In: CHARBEL, Felipe; GUSMÃO, Henrique Buarque de; MELLO, Luiza Laranjeira de S. (Orgs.) As formas do romance: estudos sobre a historicidade da literatura. Rio de Janeiro: Ponteio, 2016, p. 239-265.

DUNCAN, Ian. Scott's Shadow: the Novel in Romantic Edimburgh. Princeton, NJ: Princeton University Press, 2007.

FERRIS, Ina. The Achievement of Literary Authority: Gender, History and the Waverley Novels. Ithaca, NJ: Cornell University Press, 1991.

GALLAGHER, Noelle. Historiography, the Novel and Henry Field's. Joseph Andrews. SEL Studies in English Literature 1500-1900, v. 52, n. 3, p. 631-650, 2012.

GOODE, Mike. Sentimental Masculinity and the Rise of History, 1790-1890. Cambridge: Cambridge University Press, 2009.

\footnotetext{
${ }^{54}$ GUIMARÃES, Manoel Salgado. Reinventando a tradição: antiquarado e escrita da história, op. cit., p. 113.
} 
GOSSMAN, Lionel. Between History and Literature. Cambridge, MA: Harvard University Press, 1990.

GUIMARÃES, Manoel Salgado. Reinventando a tradição: antiquarado e escrita da história. Humanas, v. 23, n. 1/2, p. 111-143, 2000.

HARTOG, François. Regimes de historicidade: presentismo e experiências do tempo. Belo Horizonte: Autêntica, 2013.

JOHNSON, Claudia L. Equivocal Beings: Politics, Gender and Sentimentality in 1790s Wollstonecraft, Radcliffe, Burney, Austen. Chicago, IL: The University of Chicago Press, 1995.

KOSELLECK, Reinhart. Futuro passado: contribuição à semântica dos tempos modernos. Rio de Janeiro: Contraponto, 2006.

LEE, Soon Yun. A Divided Inheritance: Scott's Antiquarian Novel and the British Nation. $E L H$, v. 64, n. 2, p. 537-567, 1997.

LUKÁCS, Georg. The Historical Novel. Prefácio de Frederic Jameson. Lincoln, NE: The University of Nebraska Press, 1983.

MACK, Ruth. Literary Historicity. Literature and Historical Experience in EighteenthCentury Britain. Stanford, CA: Stanford University Press, 2009.

MAXWELL, Richard. The Historical Novel in Europe, 1650-1950. New Haven, CT: Yale University Press, 2012.

MCKEON, Michael. The Origins of the English Novel, 1600-1740. Baltimore, MD: Johns Hopkins University Press, 1997.

MILLGATE, Jane. Walter Scott: the Making of the Novelist. Edimburgo: Edinburgh University Press, 1984.

MOMIGLIANO, Arnaldo. História antiga e o antiquário. Tradução de Pedro Telles da Silveira. Anos 90, v. 21, n. 39, p. 19-76, 2014.

MULLAN, John. Anonimity: a Secret History of English Literature. Princeton, NJ: Princeton University Press, 2008.

PHILLIPS, Mark. Macaulay, Scott, and the Literary Challenge to Historiography. Journal of the History of Ideas, v. 50, n. 1, p. 117-133, 1989.

PHILLIPS, Mark Salber. Society and Sentiment. Genres of Historical Writing in Britain, 1740-1820. Princeton, NJ: Princeton University Press, 2000.

SCOTT, Sir Walter. The Antiquary. Editado por Nicola Watson. 2. ed. Oxford: Oxford University Press, 2009.

. Waverley; or, 'tis Sixty Years Since. Editado por Claire Lamont. Oxford: Oxford University Press, 2008. 
VASCONCELOS, Sandra Guardini Teixeira. A formação do romance inglês: ensaios teóricos. São Paulo: Hucitec, 2007.

WATT, Ian. The Rise of the Novel. 2. ed. Berkeley, CA: University of California Press, 2001. WELCH, Alexander. The Hero of the Waverley Novels. 3. ed. Princeton, NJ: Princeton University Press, 1992.

WOLLSTONECRAFT, Mary. A Vindication of the Rights of Woman and $A$ Vindication of the Rights of Man. Editado por Janet Todd. 3. ed. Oxford: Oxford University Press, 2008.

\section{Como citar:}

FREITAS, Renata Dal Sasso. A experiência moderna de tempo em The Antiquary (1816), de Walter Scott. Topoi. Revista de História, Rio de Janeiro, v. 19, n. 38, p. 35-57, mai./ago. 2018. Disponível em: <www.revistatopoi.org>. 